\title{
DIVERSIDADE DE FUNGOS LIQUENIZADOS DA FAMÍLIA PARMELIACEAE COLETADOS EM UM LEVANTAMENTO "RELÂMPAGO" EM LORENA, SP
}

\author{
Brendon Maximiliano Oliveira da Silva ${ }^{1}$ \\ Danielli Souza da Silva ${ }^{2}$ \\ Elenita Lourenço Leite ${ }^{3}$ \\ Kleverson dos Santos de Souza ${ }^{4}$ \\ Lorane Alice de Abreu Silva ${ }^{5}$ \\ Mayra Cristina Ferreira da Silva ${ }^{6}$ \\ Sabrina Rosa de Oliveira ${ }^{7}$ \\ Vinícius Pereira da Silva ${ }^{8}$ \\ Janaína Maria Gonçalves dos Santos ${ }^{9}$
}

\begin{abstract}
Resumo: Os liquens, associações entre fungos e algas unicelulares ou cianobactérias, são encontrados em muitos ambientes sobre vários substratos inclusive sobre troncos de árvores. Os liquens foliosos da família Parmeliaceae são bastante comuns nos ambientes brasileiros. Mesmo sendo comuns há ainda poucos levantamentos da diversidade de liquens em ambientes urbanos. Este estudo realizou um levantamento de espécies de fungos liquenizados por meio de uma coleta relâmpago em 17 forófitos de uma avenida no município de Lorena. Foram coletados 43 talos de liquens dos quais $70 \%$ são da família Parmeliaceae e estão distribuídos em seis gêneros e 21 espécies, sendo Parmotrema e Canomaculina os gêneros mais frequentes e Parmotrema tinctorum a espécie mais coletada. Pode se concluir que mesmo em ambientes não ideais, como os urbanos, há diversidade de espécies de fungos liquenizados. Palavras-chave: Liquens; Levantamento, Parmeliaceae, Parmotrema spp., Canoparmelia spp.
\end{abstract}

\footnotetext{
${ }^{1}$ Biologia/UNIFATEA, Brasil. E-mail: brendonmaximiliano@hotmail.com.

2 Biologia/UNIFATEA, Brasil. E-mail: danni.stor@hotmail.com.

3 Biologia/UNIFATEA, Brasil. E-mail: biologia@fatea.br.

${ }^{4}$ Biologia/UNIFATEA, Brasil. E-mail: kleversonss@hotmail.com.

${ }^{5}$ Biologia/UNIFATEA, Brasil. E-mail: loranesilva018@gmail.com.

${ }^{6}$ Biologia/UNIFATEA, Brasil. E-mail: mayra_cristini@hotmail.com.

${ }^{7}$ Biologia/UNIFATEA, Brasil. E-mail: sabrinarosa225@yahoo.com.br.

8 Biologia/UNIFATEA, Brasil. E-mail: vinnips11@gmail.com.

${ }^{9}$ Biologia/UNIFATEA, Brasil. E-mail: santosjanainamg@gmail.com.
} 